\title{
The Effects of Unilateral Adaptation of Hearing Aids on Symptoms of Depression and Social Activity Constraints of Elderly
}

\author{
Fernanda Dutra dos Santos ${ }^{1} \quad$ Adriane Ribeiro Teixeira ${ }^{2}$ \\ 1 Universidade Federal do Rio Grande do Sul, Curso de Especialização \\ em Audiologia, Rio Grande do Sul, Brazil \\ 2 Health and Human Comunication, Universidade Federal do Rio \\ Grande do Sul, Instituto de Psicologia da UFRGS, Porto Alegre, Rio \\ Grande do Sul, Brazil \\ Address for correspondence Adriane Ribeiro Teixeira, PhD, Health and \\ Human Comunication, Universidade Federal do Rio Grande do Sul, \\ Instituto de Psicologia da UFRGS, Rua Ramiro Barcelos, 2600, Porto \\ Alegre, Rio Grande do Sul 90035003, Brazil \\ (e-mail: adriane.teixeira@gmail.com).
}

Int Arch Otorhinolaryngol 2015;19:229-233.

\begin{abstract}
Introduction Hearing loss is one of the most common problems in the elderly population. Besides compromising oral communication, it directly affects social relations and prevents elderly patients from living actively in society, possibly leading to the onset of depression or other conditions.

Objective To analyze the effects of unilateral adaptation of hearing aids on symptoms of depression and the social activity constraints of elderly subjects with hearing impairment.

Methods The sample consisted of elderly subjects with hearing loss who did not use hearing aids. Data were collected in two phases. Initially, all participants underwent an audiological assessment and answered the Hearing Handicap Inventory for Elderly (summarized version) and the Geriatric Depression Scale. All subjects participated in the selection and hearing aid adaptation processes and became monaural hearing aid users. After 30 days of hearing aid use, they were assessed with the same instruments. The results of the questionnaires before and after hearing aid adaptation were compared.

Keywords

- hearing loss

- elderly

- hearing aids

- depression

Results The sample consisted of 13 individuals, between 60 and 90 years old (mean $72.85 \pm 11.05$ years). Data analysis showed that there was significant improvement in social activity constraints $(p<0.001)$ and in symptoms of depression $(p=0.031)$.

Conclusion Results show that, in the sample studied, unilateral hearing aid adaptation reduced social activity constraints and depression symptoms.
\end{abstract}

\section{Introduction}

Aging is part of the natural process of human development, and it brings multiple biopsychosocial changes that cause a slow and progressive deterioration of body functions that are essential to life. Among these functions that undergo important mostly irreversible changes is hearing. ${ }^{1}$ Hearing loss is considered one of the three most common conditions in the elderly, ${ }^{2}$ with occurrence of 5 to $20 \%$ in 60 -year-olds, increas-

received

June 7, 2014

accepted after revision

November 1, 2014

published online

December 22, 2014 ing to $60 \%$ in people over 65 years old. ${ }^{1,3}$ In Brazil, 60\% of the elderly have some degree of hearing loss. ${ }^{4}$

The term used to describe hearing loss associated with aging is presbycusis, which causes a decrease in hearing sensitivity and a reduction in the ability to understand speech. This occurs due to several degenerative and physiologic changes that affect the inner ear, impairing hearing at high frequencies and affecting communication, especially in noisy environments. ${ }^{1,2,4-7}$ Other factors associated with the
Copyright $\odot 2015$ by Thieme Publicações License terms Ltda, Rio de Janeiro, Brazil
DOI http://dx.doi.org/

10.1055/s-0034-1396792. ISSN $1809-9777$.

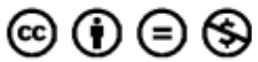


natural degeneration process, such as exposure to loud noise, ototoxic agents, and sequelae of otitis media caused by medical problems and treatments, can contribute to lifelong aggravation of the loss. ${ }^{4,8,9}$

Difficult communication associated with hearing loss can lead to social and emotional consequences, especially for the elderly, who have several limitations related to aging that can impact their quality of life, increasing social isolation in addition to causing emotional disorders such as depression. 1,4,5,8,10,11 Hearing loss-associated depression can be even more harmful in the elderly. Thus, recommended intervention by hearing aid adaptation contributes to the prevention of emotional disorders such as depression. ${ }^{12}$ Depression is defined as a mental disorder that causes feelings of sadness, pessimism, hopelessness, difficulty concentrating, and difficulty making decisions and initiating tasks, among other symptoms. ${ }^{13}$ Despite being very common in the elderly, it cannot be attributed solely to aging. Studies in São Paulo $\left(\right.$ Brazil) ${ }^{14}$ and Florianópolis (Santa Catarina, Brazil) ${ }^{15}$ showed that the factors associated with depression in the elderly are: female, unmarried or widowed, altered cognitive function, dependence, use of many medicines, very old (over 80 years), low education, poor economic status, cognitive impairment, fair or poor self-rated health, functional dependency, and chronic pain. Other causes include smoking, comorbidities (endocrine, vascular, neurologic, oncological), and negative changes in relationships with family and friends. ${ }^{15}$

Hearing loss may be associated with depression to be a debilitating, chronic disorder. ${ }^{16-18}$ The main goal of an auditory rehabilitation program in elderly patients is to minimize the effects caused by sensory deprivation of hearing and reinstate the patients in their family and society, helping them cope with the disadvantages and limitations caused by hearing loss. ${ }^{3}$

Monaural adaptations are commonly performed even in cases of bilateral hearing loss, whereas the most appropriate should be binaural adaptation. The reasons for that may be related to factors such as rejection to the use of two hearing aids, financial issues, aesthetic reasons, problems with manual dexterity, very asymmetric losses, and central processing issues. $^{19}$

Given such reality, this work intends to analyze the effects of unilateral adaptation of hearing aids on the symptoms of depression and the social activity constraints of elderly subjects with hearing impairment.

\section{Methods}

This is a prospective interventional study of elderly individuals of both sexes with recommended use of hearing aids at a hearing center in Porto Alegre. Inclusion criteria were signature of the free and informed consent; 60 years or older; good health (seniors able to commute to the research location, conduct tests, and answer questionnaires); new hearing aid users with monaural fitting; and participation in all phases of the research. Exclusion criteria were initiation of antidepressant therapy during the study and a history of cognitive and/ or neurologic disorders.
The study was divided into two phases. In phase 1 , subjects responded to an interview with questions on demographics and health (general and hearing). Next, they underwent audiological evaluation, which included meatoscopy and audiometry. Pure tone audiometry was performed to determine the airway tone thresholds (frequencies 250 to 8,000 $\mathrm{Hz}$ ) and bone conduction (frequencies 500 to $4,000 \mathrm{~Hz}$ ) in a vocal booth, using an AD-229e Interacoustics audiometer (Assens, Denmark). The presence and degree of hearing loss were classified according to the World Health Organization by analyzing mean airway tone threshold in the frequencies of $500,1,000,2,000$, and 4,000 $\mathrm{Hz}^{20}$

After that, seniors were asked to answer two questionnaires individually, without the intervention of third parties: the Geriatric Depression Scale (GDS) and the Hearing Handicap Inventory for Elderly-short version (HHIE-S).

The GDS, an instrument validated for Portuguese and composed of 15 yes-or-no questions, is used to detect depression symptoms in the elderly. To every response detected as an indication of depression, a point is assigned. Thus, scores less than 5 points indicate absence of symptoms, scores of 5 to 10 indicate mild to moderate symptoms, and scores of 11 or more indicate severe symptoms of depression. ${ }^{21}$

After completing the first phase, participants answered a summarized version of the HHIE-S. The questionnaire was prepared in $1982^{22}$ and translated and adapted to Brazilian Portuguese. ${ }^{23}$ It contains 10 questions that aim to assess the impact of hearing loss on the emotional and social status of elderly people. All 10 questions provide three choices of answers: for each "yes" answer, 4 points is assigned; each "sometimes," 2 points; and each "no," 0 points. The total score ranges from 0 to 40 points, and the higher the score, the greater subjects' self-perception of social activity constraints: 0 to 8 points indicate no social activity constraints; 10 to 23 points, mild to moderate social activity constraint; and 24 to 40 points, significant social activity constraints. ${ }^{8,22}$

After testing, the participants were subjected to the selection and unilaterally hearing aid adaptation processes. Thirty days after purchasing the device, they returned to the hearing center to participate in the second phase of the research. In phase 2, the GDS and HHIE-S instruments were reapplied.

The research project was approved by the Research Committee and by the Ethics and Research Committee of the institution (protocol 266.060). Patients who agreed to participate signed an informed consent and had their rights guaranteed for confidentiality, nonidentification, and withdrawal of participation. The chairman for the Hearing Center signed an authorization for the research.

The results were analyzed using the Statistical Package for Social Science version 20.0 (IBM, NY, USA). To examine associations of categorical data, the chi-square and Student $t$ test for paired samples were used. Values of $p<0.005$ were considered significant. All statistical tests were nonparametric tests, and always observed exact $p$ value (not asymptotic), which are the best measures to statistically evaluate a study when the sample is restricted. The chi-square test considered the $p$ value of Fisher exact test, and for the kappa coefficient of agreement, the exact $p$ value (not asymptotic) was observed. 


\section{Results}

The sample consisted of 13 elderly patients with hearing loss, ages from 60 to 90 years (mean $72.85 \pm 11.05$ years), 10 women (76.9\%) and 3 men (23.1\%). - Table 1 shows data on the characterization of sample in terms of age, gender, mean thresholds, and degree of hearing loss.

- Table 2 depicts an association analysis between the GDS classification of phases 1 and 2, indicating that there was no significant association between the variables in the periods before and after the adaptation $(p=0.615)$. Thus, of the 6 patients $(46.2 \%)$ who initially had mild symptoms of depression, only 2 (15.4\%) of them continued to have mild symptoms. All seniors who initially had severe symptoms of depression (15.4\%) also started to lose some symptoms of depression in phase 2 .

HHIE classification analysis in phases 1 and 2 of the study are presented in -Table 3. No significant association was found for these variables in the periods before and after the adaptation ( $p>0.999$ ). Thus, the only senior who had mild to moderate social activity constraints in the first phase showed reduction in the second phase. After prosthetization, participants who had severe social activity constraints in phase 1 started to show no social activity constraints or mild to moderate social activity constraints. Only 1 (7.7\%) individual had no improvement in this rating scale.

The lack of association between the classification of the GDS and HHIE on the two phases is an important point, because it shows that there were different results in both assessments (before and after hearing aid adaptation)-that is, on the sample studied, unilateral prosthetization resulted in benefits for patients.

- Table 4 shows the scores obtained by the subjects in the instruments used for evaluation in the two phases of the research. There was significant difference between the GDS $(p=0.031)$ and HHIE $(p<0.001)$ test scores when comparing the two phases.

\section{Discussion}

The analysis of the survey data showed that the age of the individuals analyzed varied from 60 to 90 years. The average found for both genders was $72.85 \pm 11.05$ years. Another study that examined the degeneration of the auditory system
Table 1 Sample characterization

\begin{tabular}{|c|c|c|}
\hline Variable & $n$ & Result \\
\hline \multicolumn{3}{|l|}{ Age $(y)$} \\
\hline Mean \pm standard deviation & 13 & $72.85 \pm 11.05$ \\
\hline Minimum & 13 & 60 \\
\hline Maximum & 13 & 90 \\
\hline \multicolumn{3}{|l|}{ Gender (\%) } \\
\hline Male & 3 & 23.1 \\
\hline Female & 10 & 76.9 \\
\hline \multicolumn{3}{|l|}{ Right ear (dB) } \\
\hline Mean \pm standard deviation & 13 & $55.67 \pm 18.11$ \\
\hline Minimum & 13 & 37.50 \\
\hline Maximum & 13 & 98.75 \\
\hline \multicolumn{3}{|l|}{ Left ear $(\mathrm{dB})$} \\
\hline Mean \pm standard deviation & 13 & $60.96 \pm 21.72$ \\
\hline Minimum & 13 & 41.25 \\
\hline Maximum & 13 & 116.25 \\
\hline \multicolumn{3}{|l|}{ Right ear classification (\%) } \\
\hline Mild & 2 & 15.4 \\
\hline Moderate & 9 & 69.2 \\
\hline Severe & 1 & 7.7 \\
\hline Profound & 1 & 7.7 \\
\hline \multicolumn{3}{|l|}{ Left ear classification (\%) } \\
\hline Moderate & 11 & 84.6 \\
\hline Profound & 2 & 15.4 \\
\hline
\end{tabular}

in the course of aging had a sample with similar age and results. $^{4}$

We had a greater number of female participants. Although it has been found that men often have more problems related to hearing loss than women, ${ }^{24}$ they also have a lower perception of their disability compared with women, ${ }^{1,25,26}$ which explains why women seek health services more often ${ }^{26,27}$ and why there is a greater number of female participants in this study. Another fact to be noted is that, in terms of population, there is a greater number of older women in Brazil, a fact known as feminization of aging. ${ }^{28}$

Table 2 Result of GDS phases 1 and 2

\begin{tabular}{|c|c|c|c|c|c|}
\hline & \multicolumn{2}{|c|}{$\begin{array}{l}\text { GDS classification } \\
\text { phase } 1\end{array}$} & \multicolumn{2}{|c|}{$\begin{array}{l}\text { GDS classification } \\
\text { phase } 2\end{array}$} & \multirow[b]{2}{*}{$p$ Value $^{a}$} \\
\hline & $n$ & $\%$ & $n$ & $\%$ & \\
\hline No depressive symptoms & 5 & 38.5 & 11 & 84.6 & \\
\hline Mild symptoms & 6 & 46.2 & 2 & 15.4 & 0.615 \\
\hline Severe symptoms & 2 & 15.3 & 0 & 0 & \\
\hline Total & 13 & 100 & 13 & 100 & \\
\hline
\end{tabular}

Abbreviation: GDS, Geriatric Depression Scale.

${ }^{\mathrm{a} C h i-s q u a r e .}$ 
Table 3 Result of HHIE phases 1 and 2

\begin{tabular}{|c|c|c|c|c|c|}
\hline & \multicolumn{2}{|c|}{$\begin{array}{l}\text { HHIE-S classification } \\
\text { phase } 1\end{array}$} & \multicolumn{2}{|c|}{$\begin{array}{l}\text { HHIE-S classification } \\
\text { phase } 2\end{array}$} & \multirow[b]{2}{*}{$p$ Value $^{a}$} \\
\hline & $n$ & $\%$ & $n$ & $\%$ & \\
\hline No perception of constrains & 0 & 0 & 9 & 69.2 & \\
\hline Mild to moderate perception & 1 & 7.7 & 3 & 23.1 & $>0.999$ \\
\hline Severe perception & 12 & 92.3 & 1 & 7.7 & \\
\hline Total & 13 & 100 & 13 & 100 & \\
\hline
\end{tabular}

Abbreviation: HHIE-S, Hearing Handicap Inventory for Elderly-short version.

${ }^{\mathrm{a} C h i-s q u a r e . ~}$

Table 4 Association analysis between the GDS and HHIE scores before and after hearing aid use

\begin{tabular}{|l|l|l|l|l|l|l|l|}
\hline & $\boldsymbol{n}$ & Mean & Standard deviation & Median & Minimum & Maximum & $\boldsymbol{p}$ Value \\
\hline GDS phase 1 & 13 & 5.69 & 4.01 & 6 & 0 & 14 & 0.031 \\
\hline GDS phase 2 & 13 & 2.69 & 2.18 & 3 & 0 & 8 & 40 \\
\hline HHIE-S phase 1 & 13 & 31.69 & 8.08 & 36 & 10 & 6 & $<0.001$ \\
\hline HHIE-S phase 2 & 13 & 6.46 & 6.89 & 6 & 0 & 24 & \\
\hline
\end{tabular}

Abbreviations: GDS, Geriatric Depression Scale; HHIE-S, Hearing Handicap Inventory for Elderly-short version.

${ }^{a} t$ test for pair samples.

There was a prevalence of moderate hearing loss in both the right and the left ears, agreeing with other published studies that refer to this as being the most commonly found degree of hearing impairment in the elderly. $2,9,25$

The data show that many seniors had some degree of depression symptoms before prosthetization (- Table 2). After unilateral hearing aid adoption, there was improvement in symptoms for most of them. Thus, a hearing aid, even when unilateral, promoted elimination or reduction of symptoms of depression in the sample studied. This result had already been described in the literature, ${ }^{2}$ but we emphasize that the result was obtained with bilateral prosthesis. Thus, the adaptation of a single amplifying device can also generate benefit for elderly patients, which is important for the reduction of one of the most prevalent problems in the aging population, depression.

The data show that all participants had some degree of social activity constraints before using a unilateral hearing aid (-Table 3). After 30 days of hearing aid use, 12 (93.3\%) and 13 (100\%) participants showed absence or reduction of social activity constraints, respectively. Results show evidence of the positive effects of hearing aid use, even if unilateral, helping to reduce the impact that hearing loss has on social relationships and on the quality of life of the elderly. ${ }^{9}$ Results are consistent with another study that examined the shortterm benefits of amplification in new users. ${ }^{29}$

The data also show a significant difference in scores obtained in phases 1 and 2 of the GDS $(p=0.031)$ and HHIE-S $(p<0.001)$, confirming a reduction or elimination of depression symptoms and social activity constraints in elderly patients, agreeing with other published studies (-Table 4). ${ }^{2,8,11,29,30}$ Again, it is important to highlight that in the studied group, unilateral prosthesis resulted in sub- stantial benefits not only regarding hearing but also in other matters essential for the well-being and quality of life of individuals.

The findings reinforce the importance of hearing aid use in elderly patients, because many times family and social relationships are affected by the hearing impairment. The adaptation to amplification devices, albeit unilaterally, has proved to be effective in reducing symptoms of depression and social activity constraints. Moreover, the length of time between assessments was 30 days, shorter than that considered ideal for auditory acclimatization, and even then, benefits occurred, confirming the importance of auditory rehabilitation in elderly.

\section{Conclusion}

Results show that unilateral hearing aid contributed to the elimination or reduction of depression symptoms and of social activity constraints in elderly participants in this research sample group.

\section{References}

1 Sousa MGC, Russo ICP. Audição e percepção da perda auditiva em idosos. Rev Soc Bras Fonoaudiol 2009;14(2):241-246

2 Teixeira AR, Thedy RB, Jotz G, Barba MC. Sintomatologia depressiva em deficientes auditivos adultos e idosos: importância do uso de próteses auditivas. Int Arch Otorhinolaryngol 2007;11(4):453-458

3 Ruschel CV, Carvalho CR, Guarinello AC. A eficiência de um programa de reabilitação audiológica em idosos com presbiacusia e seus familiares. Rev Soc Bras Fonoaudiol 2007;12(2):95-98

4 Baraldi GS, Almeida LC, Borges ACC. Evolução da perda auditiva no decorrer do envelhecimento. Rev Bras Otorinolaringol 2007;73(1): $64-70$ 
5 Almeida MR, Guarinello AC. Reabilitação audiológica em pacientes idosos. Rev Soc Bras Fonoaudiol 2009;14(2):247-255

6 Gates GA, Mills JH. Presbycusis. Lancet 2005;366(9491): 1111-1120

7 Wingfield A, Tun PA, McCoy SL. Hearing loss in older adulthood. What it is and how it interacts with cognitive performance. Curr Dir Psychol Sci 2005;14(3):144-148

8 Angeli RD, Jotz GP, Barba MC, Demeneghi PGM, Mello CHP. Effectiveness of a program of auditory prothetization in elders through the application of HHIE-S questionnaire. Int Arch Otorhinolaryngol 2009;13(3):277-280

9 Samelli AG, Negretti CA, Ueda KS, Moreira RR, Schochat E. [Comparing audiological evaluation and screening: a study on presbycusis]. Braz J Otorhinolaryngol 2011;77(1):70-76

10 Mondelli MFCG, Souza PJS. Qualidade de vida em idosos antes e após adaptação do AASI. Braz J Otorhinolaryngol 2012;78(3): 49-56

11 Marques ACO, Kozlowski L, Marques JM. Reabilitação auditiva no idoso. Rev Bras Otorrinolaringol (Engl Ed) 2004;70(6):806-811

12 Veras RP, Mattos LC. Audiologia do envelhecimento: revisão da literatura e perspectivas atuais. Rev Bras Otorrinolaringol (Engl Ed) 2007;73(1):128-134

13 Bruno CTS, Marques MB, Silva MJ. Elderly depressive disturb: the social context and environment as generators of such disturbs. Rev RENE 2006;7(1):35-42

14 Lima MTR, Silva RS, Ramos LR. Fatores associados à sintomatologia depressiva em uma coorte urbana de idosos. J Bras Psiquiatr 2009; 58(1):1-7

15 Borges LJ, Benedetti TR, Xavier AJ, d'Orsi E. Associated factors of depressive symptoms in the elderly: EpiFloripa study. Rev Saude Publica 2013;47(4):701-710

16 López-Torres Hidalgo J, Boix Gras C, Téllez Lapeira J, López Verdejo MA, del Campo del Campo JM, Escobar Rabadán F. Functional status of elderly people with hearing loss. Arch Gerontol Geriatr 2009;49(1):88-92

17 Bernabei V, Morini V, Moretti F, et al. Vision and hearing impairments are associated with depressive-anxiety syndrome in Italian elderly. Aging Ment Health 2011;15(4):467-474
18 Teixeira AR, Gonçalves AK, Freitas CLR, et al. Associação entre perda auditiva e sintomatologia depressiva em idosos. Arq Int Otorrinolaringol 2010;14(4):444-449

19 Campos CAH, Russo ICP, Almeida K. Indicação, seleção e adaptação de próteses auditivas: princípios gerais. In: Almeida K, Iorio MCM, eds. Próteses Auditivas: Fundamentos Teóricos E Aplicações Clínicas. São Paulo, Brazil: Lovise; 2003:35-54

20 Organização Mundial da Saúde. Envelhecimento Ativo: Uma Política de Saúde. Brazil: Organização Pan-Americana de Saúde; 2005

21 Almeida OP, Almeida SA. Reliability of the Brazilian version of the Geriatric Depression Scale (GDS) short form. Arq Neuro-Psiquiatr 1999;57(2B):421-426

22 Ventry IM, Weinstein BE. The hearing handicap inventory for the elderly: a new tool. Ear Hear 1982;3(3):128-134

23 Wieselberg MB. A auto-avaliação do handicap em idosos portadores de deficiência auditiva: o uso de HHIE [Dissertação]. São Paulo, Brazil: Pontifícia Universidade Católica de São Paulo; 1997

24 Lessa AH, Costa MJ, Becker KT, Vaucher AVA. Satisfação de Usuários de Próteses Auditivas, com Perda Auditiva de Graus Severo e Profundo. Arq Int Otorrinolaringol 2010;14(3):338-345

25 Flores NGC, lório MCM. Limitação de atividades em idosos: estudo em novos usuários de próteses auditivas por meio do questionário APHAB. Rev Soc Bras Fonoaudiol 2012;17(1):47-53

26 Megighian D, Savastano M, Salvador L, Frigo A, Bolzan M. Audiometric and epidemiological analysis of elderly in the Veneto region. Gerontology 2000;46(4):199-204

27 Courtenay WH. Constructions of masculinity and their influence on men's well-being: a theory of gender and health. Soc Sci Med 2000;50(10):1385-1401

28 Veras R. A era dos idosos: desafios contemporâneos. In: Saldanha AL, Caldas CP, eds. Saúde do Idoso: a arte de cuidar. Rio de Janeiro, Brazil: Interciência; 2004:3-10

29 Amorim RM, Almeida Kd. Study of benefit and of acclimatizations in recent users of hearing aids. Pro Fono 2007;19(1):39-48

30 Dan IB, Iório MC. Dificuldade e desvantagem auditivas: estudo em idosos na adaptação de próteses auditivas. Fono Atual 2004;29(7): 50-59 